Cad. Est. Ling., Campinas, 53(2):137-147, Jul./Dez. 2011

\title{
EM TORNO DE UM NOME PRÓPRIO DE CIDADE SOBRE A PRODUÇÃO DOS SENTIDOS DE UMA ORIGEM
}

\author{
EDUARDO GUIMARÃES*
}

\begin{abstract}
RESUMO: O objetivo deste trabalho é analisar o texto da lei de 1965 que atribuiu à cidade de São Vicente, em São Paulo, o título de "Cidade Monumento da História Pátria". Esta análise considera ao mesmo tempo a relação desta denominação com o movimento performativo do texto e o funcionamento das relações apositivas, presente "em Célula Mater da Nacionalidade" que também atribui sentido, na lei, ao nome próprio da cidade. Vê-se pela análise que este texto alinha o sentido de "São Vicente" a duas marcações temporais: "144. Ano da Independência e $77^{\circ}$. Da República". Nesta medida a fundação de São Vicente (primeira vila criada no Brasil) é posta na história do Brasil independente. Deste modo a criação da Vila de São Vicente está significada na sua relação com a nacionalidade e a Pátria, e assim se alinha na série criação de São Vicente (1532) - Independência do Brasil (1822) - Proclamação da República (1889).
\end{abstract}

Palavras-chave: Cidade, São Vicente, enunciação, aposto

\begin{abstract}
The aim of this study is to analyze the text of the law of 1965 that gave the city of São Vicente, in the state of São Paulo - Brazil, the title of "City Monument Of Country's History". This analysis considers both the relation of that name with the performative movement of the text and the functioning of appositive relations, present in "Main Cell of Nationality", which also, in the law, gives meaning to the name of the city. The analysis shows that the text of the law aligns the meaning of São Vicente with two temporal markings: " $144^{\text {th }}$ Year of the Independence and $77^{\text {th }}$ of The Republic". To this extent, the foundation of São Vicente (the first village established in Brazil) is placed in the history of Brazil as an independent country. Thus the creation of the village of São Vicente is meant in relation to the Brazilian nationality and homeland, and thus aligns in the series "creation of SãoVicente (1532) - Brazil's Independence (1822) - Proclamation of the Republic (1889)".
\end{abstract}

Keywords: city, São Vicente, enunciation, appositive

Em 20 de março de 1965, a lei no. 4.603 do congresso Nacional, sancionada pelo Presidente da República, atribui à cidade de São Vicente, do Estado de São Paulo, a denominação de "cidade Monumento da História Pátria".

Para compreender os sentidos deste acontecimento de enunciação, na história da cidade $^{1}$, vamos analisar o texto da lei que atribui a ela esta denominação. É um texto curto cujo objeto está no art $1^{\circ}$.:

${ }^{*}$ DL - IEL/Labeurb/Unicamp

${ }^{1}$ Procuramos aqui avançar para uma abordagem da história das cidades brasileiras, a partir da posição que temos desenvolvido na linha de pesquisa "saber urbano e linguagem" do Laboratório de Estudos Urbanos. Estes desenvolvimentos podem ser encontrados em obras como Orlandi, E. (2004); Orlandi (org.) (2001 e 2010) e Guimarães (2002). 
T-1 - $\quad$ LEI No 4.603, DE 20 DE MARÇO DE $1965^{2}$

Concede a denominação de "Cidade Monumento da História Pátria” à Cidade de São Vicente, no Estado de São Paulo.

O PRESIDENTE DA REPÚBLICA, faço saber que o CONGRESSO NACIONAL decreta e eu sanciono a seguinte lei:

Art. $1^{\circ}$ À Cidade de São Vicente - Célula Mater da Nacionalidade - é concedida, em caráter excepcional, a denominação de "Cidade Monumento da História Pátria".

Art. $2^{\circ}$ Esta lei entra em vigor na data de sua publicação.

Art. $3^{\circ}$ Revogam-se as disposições em contrário.

Brasília, 20 de março de $1965 ; 144^{\circ}$ da Independência e $77^{\circ}$ da República.

H. CASTELLO BRANCO

Raimundo Moniz de Aragão

Para esta análise vou considerar, enquanto semanticista ${ }^{3}$, três recortes fundamentalmente: o modo de agenciamento performativo do texto; o nome da cidade e sua articulação com a denominação atribuída pela lei; e os sentidos das determinações que o texto atribui ao nome e à cidade.

\section{O AGENCIAMENTO CIRCULAR}

A performatividade desta lei se formula como fundada no Congresso Nacional e sancionada pelo Presidente da República. No entanto, como já tive ocasião de mostrar em estudos anteriores ${ }^{4}$ sobre a questão da cidadania e da república no Brasil, o Presidente da República, neste período da história do país, tem o poder legitimado pelas forças armadas que se apresentam, nas relações de enunciações dos anos 1960, como a sustentação do próprio Congresso. Para isso retomemos uma formulação, decisiva deste ponto de vista, que consta do preâmbulo do ato institucional de 9 de abril de 1964, que sustenta o "ordenamento jurídico" do poder naquele momento:

(1) "A revolução vitoriosa se investe no exercício do Poder Constituinte. Este se manifesta pela eleição popular ou pela revolução. Esta é a forma mais expressiva e mais radical do Poder Constituinte. Assim, a revolução vitoriosa, como Poder Constituinte, se legitima por si mesma."

(2) "Para reduzir ainda os plenos poderes de que se acha investida a revolução vitoriosa, resolvemos, igualmente, manter o Congresso Nacional, com as reservas relativas aos seus poderes, constantes do presente Ato Institucional (...) Fica assim, bem claro, que a revolução não procura legitimar-se através do Congresso. Este é que recebe deste

\footnotetext{
2 Encontrado no site do Senado: WWW6.senado.gov.br/legislação/
} ListaNormas.action?numero=4603\&tipo_norm...

${ }^{3}$ Esta análise será feita segundo procedimento que apresento em Guimarães (2011).

${ }^{4}$ Em outros Guimarães (1991, 1992a, 1995, 1996). 
Ato Institucional, resultante do exerecício do Poder Constituinte, inerente a todas as revoluções, a sua legitimação."

O que temos então é que o Presidente da República, enquanto membro da mais alta hierarquia militar (ele era um marechal) diz sancionar uma lei que é apresentada por um congresso cuja legitimidade performativa está dada pelas forças armadas, que, nos trechos acima, afirmam ter feito uma revolução que é apresentada pela enunciação como a garantia constituinte "mais radical".

Ou seja, o que se tem não é uma origem específica para o valor performativo da enunciação. Estamos diante de um lugar de sujeito que sanciona uma lei de um congresso que este mesmo lugar de sujeito (o das Forças Armadas) estatuiu. O dizer do Congresso e o do Presidnete enunciam a partir de um dizer das Forças Armadas. O performativo da lei tem sua garantia neste agenciamente político do locutor.

Um outro aspecto interessante deste modo de agenciamento é que ele se apresenta como uma informação: o presidente da república faz saber, que se apresenta na fórmula "o presidente da república faço saber", que significa por um movimento que vai da terceira para a primeira pessoa, e aquela agenciada por uma outra terceira pessoa: as forças armadas, "a revolução".

\section{O NOME DA CIDADE E SUA ARTICULAÇÃO NO ENUNCIADO}

A primeira coisa a observar é que a denominação de que trata a lei é apresentada no enunciado:

(4) Art. $1^{\circ}$ À Cidade de São Vicente - Célula Mater da Nacionalidade - é concedida, em caráter excepcional, a denominação de "Cidade Monumento da História Pátria".

Nele encontramos uma expressão referencial, "a cidade de São Vicente”, a cujo lugar referido atribui-se a denominação "Cidade Monumento da História Pátria".

A primeira destas expressões referenciais contém um nome próprio de lugar (uma cidade). E este nome é atribuído a este lugar no século XVI, num processo de ocupação de território pela colonização portuguesa. Tome-se como referência o relato de Abreu no seu Capítulos de História Colonial:

"Depois da perda da capitanea passou Martim Affonso a tratar da segunda parte da sua missão: o povoamento da terra. Em S. Vicente fundou a primeira villa, á beira-mar;"' (Abreu, 1907, p. 32)

O nome da cidade, São Vicente, traz a marca do lugar religioso das nomeações que está no primeiro nome dado ao Brasil pelos portugueses: "Ilha (Terra) de Vera (Santa) Cruz".5

O lugar da nomeação é assim oficial e marcado pela relação indiscernível, naquele momento, entre Estado e Igreja. Assim o nome São Vicente a que a lei de que tratamos aqui

\footnotetext{
${ }^{5}$ Sobre esta nomeação ver Guimarães (1992b).
} 
atribui uma denominação tem, pela cena de sua nomeação, um sentido religioso. O próprio nome do lugar é tomado do nome de um Santo da Igreja Católica.

Dando andamento à análise da formulação da denominação que a lei estabelece, um aspecto a observar é que a expressão "Cidade Monumento da História Pátria” aparece em dois momentos do texto. Primeiro aparece na ementa da lei, cujo enunciado se apresenta como uma informação do que a lei faz. Mas este enunciado não está formulado pelo locutor que legisla ou sanciona, ele está enunciado por um locutor administrativo que informa de que lei se trata. A denominação é depois, no texto, reescriturada por repetição na voz do locutor-legislador que efetivamente atribui a denominação. De fato podemos dizer que o que está no artigo $1^{\circ}$. na voz do locutor-legislador é que é reescrito, depois, mas que, na segmentalidade do texto, se anuncia antes, como um anúncio do poder do legislador. Assim a atribuição da denominação aparece como instalada pelo agenciamento performativo de que tratamos logo acima.

Cabe agora uma atenção mais específica sobre o modo como a denominação está apresentada. Analisemos em detalhe o enunciado do artigo $1^{\circ}$.

(4) Art. $1^{\circ}$ À Cidade de São Vicente - Célula Mater da Nacionalidade - é concedida, em caráter excepcional, a denominação de "Cidade Monumento da História Pátria".

Neste artigo $1^{\circ}$., central no texto, a atribuição da denominação, motivo da lei, é apresentada como uma especificação da formação nominal sujeito do enunciado. Olhando mais em detalhe ainda vemos que a denominação em estudo aparece como uma especificação numa formação nominal sujeito de um enunciado passivo, sem que se diga no próprio enunciado o agente que denomina. Assim a denominação é significada como o centro do que se enuncia. Não "interessa” quem atribui a denominação, mas quem a recebe e como. A denominação aparece pelo sentido que atribui, como algo que lhe seja próprio, a $\mathrm{S}$. Vicente: monumento da história do país (da pátria). No entanto a relação deste enunciado com o texto em que está integrado nos dá o agente da denominação: o lugar do legislador agenciado do lugar das forças armadas, tal como estabelecido pela análise da performatividade. E assim não podemos deixar de perguntar como esta relação do lugar do locutor com o que é enunciado significa no texto.

Esta pergunta leva a considerar dois elementos que produzem determinações de sentido no nome da cidade neste acontecimento de enunciação: a predicação que se atribui a São Vicente e a formação apositiva que acompanha o nome da cidade no complemento da formação predicativa: Célula Mater da Nacionalidade.

Antes de analisar os sentidos destas duas expressões, consideremos o funcionamento do aposto.

\section{REESCRITURAÇÃO APOSITIVA}

Para refletir sobre este aspecto, tomemos um enunciado recortado de um outro texto: 
(5)O primeiro é baseado no diário do viajante alemão(a) Staden(b), feito prisioneiro pelos índios tupinambás(c) - adeptos do canibalismo(d) - no Brasil do século XVI ${ }^{6}$.

Em (5) temos uma formação apositiva em “adeptos do canibalismo” (d). Esta expressão reescritura, por especificação (expansão), "índios tupinambás", e nesta medida determina o sentido desta última expressão (a “índios Tupinambás” está atribuído o sentido de "adeptos do canibalismo").

Por outro lado poderíamos pensar na seguinte paráfrase de (5):

(5a) O primeiro é baseado no diário do viajante alemão Staden, feito prisioneiro pelos índios tupinambás no Brasil do século XVI.

(5b) Os tupinambás são adeptos do canibalismo.

Relativamente a esta paráfrase, podemos considerar que se tomarmos o enunciado negativo (5c), vemos que a negação em nada afeta o sentido de (d):

(5c) O primeiro não é baseado no diário do viajante alemão (a) Staden(b), feito prisioneiro pelos índios tupinambás(c) - adeptos do canibalismo(d) - no Brasil do século XVI.

Neste caso (d) continua parafraseável por (5b).

Por outro lado, se tomamos o modo de marcar por travessões a inserção de (d) em (5), vemos que ela não se deu por algo como,

(5b') que eram adeptos do canibalismo.

Vemos que o deslize do narrado para o presente (a característica da antropofagia que está significada no presente, mesmo que isto não seja mais verdade) nos leva a considerar uma divisão desta enunciação em dois enunciadores (consideremos que o lugar social do locutor é o de jornalista (1-jor), já que o texto é uma "notícia" em uma revista de divulgação científica):

\begin{tabular}{r|r} 
& $E 1-(5 b)$ \\
$L-1$-jor & E2 $-(5 a)$
\end{tabular}

Isto nos mostra que a reescrituração apositiva atribui sentido ao reescriturado a partir de um outro lugar de dizer, diverso daquele do qual se diz aquilo que se reescritura.

Um outro aspecto a considerar: (d) pode também, em certa medida, ser parafraseado por

(5b”) Os tupinambás, todos sabemos, são adeptos do canibalismo.

${ }^{6}$ No texto "A linguagem em Desmundo e Como era gostoso o meu francês", Ciência e Cultura, ano 57, no. 2, SBPC, junho de 2005, p. 51. 
Pode-se, então, considerar que E-1 é, neste caso, um enunciador genérico (Egco). Considero que se trata de um Egco, já que em (d) há o deslize que procurei indicar pelo fato de que a formação apositiva se diferencia de (5b') e funciona difusamente nos sentidos atribuídos aos índios na história do Brasil. Esta voz genérica traz um sentido como memorável (nesta cena junto com o presente afirmado em (5a)). Ao mesmo tempo aí há um futuro de sentidos criado pela afirmação da permanência dos tupinambás como adeptos do canibalismo. Este futuro não seria o mesmo se (d) fosse

(5b') que eram adeptos do canibalismo.

Vamos agora observar uma outra expressão a que não tínhamos feito atenção até aqui, a expressão (c), deixemos, provisoriamente, de lado o (d). Aqui também devemos considerar que "feito prisioneiro pelos tupinambás" reescreve, por expansão, Staden. Podemos também considerar a seguinte a paráfrase:

(5e) O primeiro é baseado no diário do viajante alemão Staden no Brasil do século XVI.

(5f) Staden foi feito prisioneiro pelos tupinambás.

Se considerarmos a negação de (5), isso em nada afeta (5f), e (c) pode ser, parafraseado por

(5f’) Staden, como se sabe, foi feito prisioneiro pelos tupinambás.

Assim temos também algo parecido com o que consideramos para a análise de (d):

$$
\begin{array}{l|l}
\mathrm{L}-1-\mathrm{E} 1-(5 \mathrm{f}) \\
\mathrm{E} 2-(5 \mathrm{e})
\end{array}
$$

Aqui, mais uma vez há dois Enunciadores. E-1 pode ser interpretado, no caso, como um E-universal (uma voz que se coloca no lugar do dizer histórico). Ou seja, o lugar do qual se diz a reescrituração é diverso daquele do qual se diz o reescriturado.

Vamos agora para (b) que incide sobre "viajante alemão". Aqui teríamos a seguinte paráfrase para (5):

(5g)O primeiro é baseado no diário do viajante alemão no Brasil do século XVI.

(5h) o viajante alemão é Staden

Nesta paráfrase temos que considerar que (5h) é paráfrase de

(5h’) O viajante alemão é o mesmo que Staden

Que leva necessariamente a 
(5h”) Staden é o mesmo que o viajante alemão.

Isto nos leva a dois aspectos interessantes. De um lado vamos considerar que a formação apositiva em lugar de expandir, substitui o reescriturado. Isto traz uma característica que precisa ser aprofundada relativamente ao funcionamento do nome próprio na formação apositiva. De outro lado, e isto tem a ver com o acabamos de dizer, (5h) nos leva à paráfrase

(5i) Staden é (o viajante) alemão.

Isto está ligado a que, na medida em que a reecrituração é por substituição, ela pode ser tomada como sinonímica, de tal modo que podemos considerar que o reescriturado (viajante alemão) determina a reescrituração (Staden). O que pode ser considerado como relacionado ao funcionamento dos nomes próprios. Isto nos leva a um importante aspecto das reescriturações apositivas: se o nome próprio é uma reescrituração de outra expressão nominal, a determinação pode ser tomada como do reescriturado para a reescrituração, ou seja é alemão (e viajante) que determina o sentido de Staden. Este aspecto é importante para se pensar a questão do sentido dos nomes próprios ${ }^{7}$. Por outro lado, podemos considerar nesta medida que o parafraseamento de (5) para este caso deve ser:

(5g.1)O primeiro é baseado no diário de Staden no Brasil do século XVI.

(5h.1) Staden é o viajante alemão.

(5i.1) Staden é alemão.

Assim chegamos à seguinte cena enunciativa:

$$
\begin{array}{l|l}
\text { L-1-jor } & \text { E1 }-(5 \mathrm{~h} .1) \\
& \text { E2 }-(5 \mathrm{i} .1) \\
& \mathrm{E} 3-(5 \mathrm{~g} .1)
\end{array}
$$

Neste caso E1 e E2 podem ser interpretados, dadas as considerações acima, como um E-gco, distinto de E-3 (individual).

Isto mostra que a reescrituração apositiva se dá sempre por um desdobramento de enunciadores. No conjunto pode-se dizer que o Locutor é tomado pelo enunciador-individual que enuncia o elemento determinado da reescrituração apositiva.

Voltemos à nossa análise.

\section{REFAZENDO OS SENTIDOS DE UM NOME}

No enunciado do artigo $1^{\circ}$. Vamos encontrar o nome da cidade, "São Vicente", reescriturado apositivamente por "Célula Mater da Nacionalidade". Assim o sentido do

\footnotetext{
${ }^{7}$ Aspecto que estou tratando em outro texto sobre nomes próprios e formação apositiva.
} 
nome próprio "São Vicente" fica determinado pelo sentido da formulação apositiva. Por outro lado, segundo nossa análise da formação apositiva, podemos considerar que o enunciador de cujo lugar se enuncia o nome é diverso do enunciador da reescrituração que determina e produz sentido.

Temos algo como:

L:

E1 (ind.) -Art. $1^{\circ}$ À Cidade de São Vicente é concedida, em caráter excepcional, a denominação de "Cidade Monumento da História Pátria".

E2 (gco) - São Vicente é a Célula Mater da Nacionalidade

Onde L é tomado por E1 e está incluído em E2. Ou seja, o que está significado por E2 é significado como algo de uma voz genérica que inclui L. E qual o sentido do que diz esta voz genérica, portanto difusa e dada como já conhecida por todos? Para responder a esta pergunta devemos levar em conta que o enunciado em análise tem relação com outros textos da história que afirmam que São Vicente foi a primeira Vila criada no Brasil, por Martim Afonso, em 1532. Sua nomeação é deste momento da história e significa a relação Estado-Igreja tal como já dissemos acima. E aqui mais uma pergunta, o que significa neste acontecimento apresentar já uma denominação apositiva como Célula Mater da Nacionalidade e ainda acrescer-lhe outra denominação, agora dada como do presente do acontecimento: Cidade Monumento da História Pátria?

O primeiro aspecto a considerar é que a enunciação do enunciador genérico, que reescreve o nome da cidade apositivamente, se apresenta como um sentido dado como conhecido, ou seja, trata-se de uma enunciação pressuposta que se apresenta como condição para a enunciação do artigo $1^{\circ}$. Desta maneira a denominação formulada pelo locutorlegislador toma a pressuposição do aposto como o quadro no qual se enuncia a denominação. Neste sentido podemos considerar que a denominação concedida é uma reescrituração por especificação do nome "São Vicente". Nesta medida esta denominação determina o sentido do nome "São Vicente" e é determinado pelo sentido do aposto.

Veja, quanto à determinação de "São Vicente" pela denominação atribuída, que se tomamos:

(4a1).À Cidade de São Vicente é concedida, em caráter excepcional, a denominação de "Cidade Monumento da História Pátria".

Podemos considerar a seguinte paráfrase:

(4a1') 'Cidade Monumento da História Pátria é um outro nome para São Vicente que equivale a

(4a1”) Um outro nome para São Vicente é Cidade Monumento da História Pátria. 
O que confirma o que acabamos de dizer, que "cidade monumento da história pátria" determina "São Vicente”. Ou seja, a nova denominação não é um novo nome próprio, mas um atributo que é dado à cidade.

Por outro lado, quanto à determinação da denominação pelo aposto, podemos considerar a seguinte paráfrase:

\section{(4a2) A Célula Mater da Nacionalidade é a Cidade Monumento da História Pátria.}

O que torna interessante o que encontramos pela paráfrase (4a2) é que, no enunciado do texto, "Célula Mater da Nacionalidade" está na voz de um enunciador genérico e "Cidade Monumento da História Pátria" na voz de uma enunciador Individual. Mais que isso, "Cidade Monumento da História Pátria" é uma denominação assumida pelo locutor-legislador, enquanto "Célula Mater da Nacionalidade", na voz genérica, agencia o Locutor, cuja voz se inclui na voz genérica.

Assim este texto agencia um lugar que denomina São Vicente de "Cidade Monumento da História Pátria" tomando, como sua história de enunciações, um passado deste acontecimento, as enunciações do golpe militar que 1964. E nesta relação, ao se enunciar a denominação, ao atribuí-la a algo, projeta-se um futuro de sentidos no qual passa a caber a afirmação, impossível até então,

(3)"São Vicente é a cidade monumento da História Pátria".

Ou mesmo, algo como

(3a) São Vicente, cidade monumento da História Pátria, receberá hoje...

Mas voltemos a

(4a2) A Célula Mater da Nacionalidade é Cidade Monumento da História Pátria.

Estamos diante de uma paráfrase que traz uma atribuição de sentidos que se apresenta no texto de modo não homogêneo. Por outro lado vemos emparelharem-se dois nomes cuja história de sentidos caminha muitas vezes de modo paralelo e articulado: nacionalidade e Pátria. E isto articula metáforas como "célula mater" de um lado e "cidade monumento" de outro.

Como vimos a afirmação da história pátria, está na voz do locutor-legislador cujo agenciamento performativo é produzido pelo lugar das forças armadas, e de outro temos uma voz genérica que sustenta o sentido da nacionalidade que, como vimos, determina o sentido da nomeação nova. Ou seja, nacionalidade determina, mais uma vez, o sentido da pátria.

E como já pudemos dizer, o sentido desta reescrituração apositiva e da denominação atribuída reporta a enunciações da história do Brasil que dão conta de que São Vicente foi a primeira Vila fundada, por Martim Affonso de Souza, no Brasil. Tomemos uma formulação tirada de uma obra considerada clássica da história colonial brasileira: 
(5)'Depois da perda da capitanea passou Martim Affonso a tratar da segunda parte da sua missão: o povoamento da terra. Em S. Vicente fundou a primeira villa, á beiramar;" (Abreu, 1907, p. 32)

Nesta medida, a fundação da vila de São Vicente é apresentada como a fundação de uma vila no porto de S. Vicente. E como parte da missão de povoar a terra. Assim nos deparamos com uma apresentação da fundação da Vila de São Vicente significa no esforço de ocupação da terra pelo povoamento. Assim já vemos uma distância entre o sentido dado à fundação no relato histórico e o sentido dado a ela pela lei de 1965, que está no texto que aqui analisamos.

Para tornar esta questão mais específica, podemos tomar uma passagem de um Relatório, de 1553, de Tomé de Souza a respeito da fundação de Santos, logo depois da fundação de S. Vicente:

(6) "S. Vicente, capitania de Martim Afonso, é uma terra muito honrada e de grandes águas e serras e campos. Está a vila de S. Vicente situada em uma ilha de três léguas de comprido e uma de largo, no qual ilha se fez outra vila que se chama Santos, a qual se fez porque a de S. Vicente não tinha bom porto e a Santos que está uma légua da de S. Vicente tem o melhor porto que se pode ver e todas as naus do mundo poderão estar nele com os proízes dentro em terra. (Alves Filho, 1999, p. 57)

Ou seja, já muito cedo, no gesto de ocupação e proteção do território da colônia, vemos a afirmação de um documento oficial informando que Santos tem melhores condições de ser o porto de que se necessita. E a afirmação sobre o porto de S. Vicente já está dada numa forma do imperfeito, em contraste com a afirmação sobre o porto de Santos no presente. S. Vicente aparece neste relato referida no passado.

O acontecimento da denominação em análise se movimenta ao avesso disso. Assim é que a fundação de S. Vicente está no texto alinhada a duas marcações temporais: "144”. Ano da Independência e $77^{\circ}$. Da República”. A fundação de São Vicente é posta na história do Brasil independente. No texto aqui analisado, a criação da Vila de São Vicente está significada na sua relação com a nacionalidade e a Pátria, e assim se alinha na série criação de São Vicente (1532) - Independência do Brasil (1822) - Proclamação da República (1889).

\section{CONCLUSÃO}

Uma primeira coisa a dizer: estamos diante de um texto que atribui um papel especial na conformação da nacionalidade e assim da Pátria à constituição de cidades. Num momento, década de 1960, em que o Brasil se movimenta de uma predominância de vida rural para a predominância da vida urbana, a criação da primeira vila estabelecida oficialmente no Brasil (1532) toma o sentido de origem da nacionalidade e é isto que determina o sentido de "Cidade Monumento da história Pátria". 
Neste movimento encontramos a atribuição de uma denominação, de uma predicação, diríamos, ao sentido de uma cidade, que atribui de modo deslocado o sentido da origem da nacionalidade. Trata-se de atribuir o sentido de origem da nacionalidade à criação de uma vila que foi estabelecida como um movimento inicial da ocupação portuguesa do território da colônia para permitir uma melhor defesa do território. Em certa medida trata-se de um anacronismo: a lei aqui analisada atribui um sentido resultante de um longo processo histórico (uma identidade brasileira) a um fato que no seu início é significado como ocupação de um outro lugar, e não como identidade. Neste sentido o texto está numa rede de significação que inventa um passado para a nacionalidade brasileira.

Deste modo o locutor-legislador, tomado pelo nacionalismo do lugar das forças armadas, produz uma ressignificação radical, a nacionalidade brasileira se instala mesmo antes de qualquer história brasileira. Este tipo de formulação, ao lado de se dar como de dentro da ditadura, se faz ao modo dos movimentos identitários que formulam a identidade como permanência (ao modo culturalista) e cuja garantia é uma origem "reivindicada", não histórica. Trata-se de uma projeção do presente da enunciação da ditadura sobre a história colonial, tomada como um percurso "sem tropeços".

\section{REFERÊNCIAS BIBLIOGRÁFICAS}

ABREU, C. (1997). Capítulos de História Colonial. Rio de Janeiro: M. Orosco \& C.

ALVES FILHO, I. (1999). Brasil, 500 anos em Documentos. Rio de Janeiro: Mauad.

GUIMARÃES, E. R. J. (1991). Os Sentidos da República no Brasil. Pro-Posições, 5 (Unicamp), São Paulo. . (1992a). Os Sentidos de Cidadão no Império e na Repúbica no Brasil. Signo e Seña, Revista del Instituto de Linguistica. Buenos Aires.

. (1992b). Terra de Vera Cruz, Brasil. Revista de Cultura Vozes. São Paulo.

(1995). L'autoritarisme constitutionnel au Brésil. Mots, n. 43, Paris.

. (1996). Os Sentidos de Cidadão no Império e na República. In: Eduardo Guimarães. (Org.). Língua

e Cidadania. Campinas: Pontes.

. (2002). Semântica do Acontecimento. Campinas: Pontes.

. (2011). Análise de Texto. Procedimentos, Análises, Ensino. Campinas: RG.

ORLANDI, E. P. (2004). Cidade dos Sentidos. (1a. edição: 2004, Ed. Pontes). Campinas: Pontes.

(Org.) (2001). Cidade Atravessada - Os sentidos do público no espaço urbano. Campinas: Pontes.

(Org.) (2010). Discurso e Políticas Públicas Urbanas - A Fabricação do Consenso. Campinas:

Editora RG. 